\title{
Educating Dentists about Fissure Sealants: Effects on Knowledge, Attitudes, and Use
}

\author{
W. Paul Lang, DDS, PhD \\ Mahassen M. Farghaly, BDS, MPH \\ Marilyn W. Woolfolk, DDS, MPH \\ School of Dentistry \\ University of Michigan \\ Ann Arbor, MI
}

Thomas L. Ziemiecki, DDS, MS

School of Dental Medicine

University of Connecticut

Farmington, CT

\section{Barbara W. Faja, MPH}

School of Dentistry

University of Michigan

Ann Arbor, MI

\begin{abstract}
This study evaluated the effects of three modes of education on dentists' knowledge, attitudes, and use of pit and fissure sealants. A randomly selected group of dentists was invited to participate in a sealant education initiative. During a 12-month period, a total of 662 dentists either (1) attended continuing education courses, (2) received written materials and videotapes by mail, or (3) received only written materials by mail. A comparison group ( $n=337$ ) received no materials until after the education phase and evaluation had been completed. Preand postintervention surveys were used to measure changes in knowledge, attitudes, and sealant use. Response rates to the two surveys were 62 percent and 76 percent, respectively. Preintervention values for knowledge scores, an attitude scale, and sealant use were similar among the four groups. At followup, the three education groups had significantly higher knowledge scores than the comparison group. Attitude values for all but one group were not significantly different, and sealant use by all groups was identical. The numbers of respondents not using sealants declined slightly between surveys in the three education groups while rising slightly in the No-Education Group. Because program outcomes were similar to those of another sealant initiative, it can probably be concluded that continuing education will increase dentists' knowledge about sealants, but have
\end{abstract}

Send correspondence and reprint requests to Dr. Lang, Department of Periodontics/Prevention and Geriatrics, 1014 Kellogg Building, School of Dentistry, University of Michigan, Ann Arbor, MI 48109-1078. Supported by the American Fund for Dental Health and DHHS PHS G-2 S07 RR 05321. Manuscript received: 3/19/90; returned to authors for revision: 5/23/90; accepted for publication: $8 / 28 / 90$. little effect upon their attitudes or their use of the technique. The changes observed in this investigation may be due to the particular capacity for cognitive and affective changes of participants, characteristics of the technology being promoted, and external forces in the professional environment.

Key Words: pit and fissure sealants, continuing dental education, program evaluation, knowledge, attitudes, practice.

The adoption of pit and fissure sealants by dentists can be traced in survey research of the preceding two decades. Surveys completed in the 1970 s indicated that fewer than 40 percent of general dentists were using sealants $(1,2)$. Utilization increased to about 60 percent in the early 1980s $(3,4)$. Recent surveys indicate that 69-88 percent of respondents are applying sealants (5-8). Dentists have generally adopted the technique, but when frequency of application is examined, a less favorable picture emerges. For example, 88 percent of general dentists responding to a 1987 survey in Michigan reported using sealants (7). However, of the dentists who were using the technique, about 44 percent were applying sealants infrequently (on fewer than $6 \%$ of their younger patients) while another 30 percent reported moderate use (on 6-20\% of younger patients). Low frequency of sealant use has been reported in other surveys $(4,6,8)$. Given a recent estimate that 45 percent of first and second grade children need sealants (9), the diffusion of this technology should be considered incomplete. 
Lack of knowledge about sealants frequently has been cited as a possible deterrent to professional adoption $(1,4,5)$. When dentists' knowledge was assessed in a 1985 national survey of sealant use, findings indicated "a great degree of confusion surrounding the facts about sealants" (6). A conclusion of a state survey conducted in the same year was that "... a lack of professional knowledge about sealants continues to exist" (5). Continuing education has been proposed as a method for increasing sealant utilization among practicing dentists, with dental schools being the likely sponsors of such courses $(5,10,11)$. Unfortunately, efforts to facilitate continuing education for health professionals have been limited $(11,12)$. Barriers to the provision of continuing education are not trivial and include resource and personnel constraints placed on sponsoring agencies, poorly publicized courses, geographical separation of participants, and course fees that may discourage attendance (13).

\section{"Lack of knowledge about sealants frequently has been cited as a possible deterrent to professional adoption."}

Despite these difficulties, some notable continuing education initiatives have been undertaken. A sealant continuing education course was developed for dental professionals by Scheirton (13). Clinical competency and routine sealant use were the anticipated outcomes of the course. Competency was assessed at the time of participation, but changes in sealant use were not reported. Professional education was one component of a sealant promotion program sponsored by the Massachusetts Department of Public Health (14). Continuing education was provided to over 600 dental professionals in statewide presentations. Increased sealant use was anticipated because of the broad-based nature of the initiative that included a demonstration component, consumer education, and a reimbursement component focused on third party insurers. In North Carolina, continuing education was used as part of a statewide sealant initiative (15). While continuing education participants demonstrated modest improvements in knowledge and attitudes toward sealants, no differences in sealant use were found between participants and nonparticipants. Lack of association between sealant use and continuing education participation has been observed by other investigators (8).

This paper reports the evaluation of a program that would function as a change agency to increase sealant use among dentists in Michigan. Information about sealants was provided to dentists in three formats: continuing education courses, mailed written material and videotapes, or mailed written material only. The goals of the project were (1) to determine whether dentists' knowl- edge, attitudes, and use of sealants could be modified by education; and (2) to assess the relative success of the educational formats in effecting change. An implicit feature of the program was to provide information to as many dentists as resources would permit, in order to fulfill a complementary service mission.

\section{Methods}

Subjects. The names, addresses, years of birth, and years of licensure of dentists in four areas of Michigan were obtained from the Michigan Department of Licensing and Regulation (16). The four areas were selected as program sites based on geographic proximity and concentrations of dentists. General and pediatric dentists in these areas $(N=2,203)$ were surveyed to gather baseline data on their attitudes and knowledge about sealants and frequency of sealant applications. About two-thirds of respondents were randomly selected to participate in the education component of the program (Education Group, $n=923$ ). Continuing education courses, videotapes, and materials were offered to this group by using repeated mailings. The remaining dentists (No-Education Group, $n=438$ ) were not offered any materials until after a followup survey. This second survey was mailed 18 months later to baseline respondents only.

Evaluation. A 26-item questionnaire was developed for the project using knowledge, attitude, and sealant use questions from other investigations (1-4). Knowledge and attitude items were selected from existing instruments for their likelihood to measure the program's educational objectives. Items were positively and negatively worded. Twelve questions were used to measure dentists' knowledge about appropriate teeth for sealing, sealant longevity, and delegation of sealant applications to auxiliaries. A three-point scale (agree, undecided, disagree) was used with these items. For analysis, the scale was collapsed to right or wrong with "undecided" being placed in the wrong category. A knowledge score for each participant was attained by summing the number of correct responses (range $=0-12$ ). Six questions were used to measure dentists' attitudes about the value of sealants, the ease of sealant application, the ease of sealant promotion to patients, and the practicality of sealants in private practice. A five-point Likert scale was used with these six items ( $5=$ =ositive attitude, $1=$ negative attitude), and an attitude scale was constructed with a range of 6-30 (Cronbach's alpha=.63). Sealant use was assessed by requesting the percentage of patients in the practice aged 18 years and younger who were receiving sealants.

The questionnaire was pretested on a random sample of 35 dentists from the program areas. The followup questionnaire contained the same attitude, knowledge, and use questions. Four additional items from a previous initiative were used to assess practice changes in patient acceptance of sealants, respondents' perceptions of success or failure at increasing sealant use, and knowledge 
gained during the program year (15). Questionnaires and complete item results are available from the authors.

Analysis of variance with the Scheffé multiple comparison procedure was used to determine significant differences between groups for mean knowledge scores and attitude scale values. Sealant use and practice changes were analyzed using the median and chi-square tests. Data were analyzed only for subjects responding to both surveys.

Provision of Education. The education component of the program was 12 months long and commenced in the fall of 1987. Dentists invited to participate in the program were given the opportunity to attend a continuing education course on sealants and receive materials through the mail. Courses and initial bulk mailings occurred over a six-month period; six additional mailings were sent to all participants at monthly intervals.

\section{"When improvements in knowledge scores and perceived information gain of the three education groups were compared to similar values of the No-Education Group, we concluded that knowledge acquisition was a program achievement."}

The continuing education course was a half-day program consisting of lectures, audiovisual presentations, and a laboratory session. The scientific rationale for sealants, the physical characteristics of sealants, polymerization techniques, and sealant delivery systems were described. Scientific studies of sealants were reviewed, with emphasis on longevity of sealants, effects of tooth eruption, effects of proper tooth isolation, and caries susceptibility with sealant loss. Criteria for diagnosis of caries were reviewed, as were criteria for tooth selection. Sealant application procedures were outlined along with reapplication techniques. Other topics included delegation of sealant application to auxiliaries, reimbursement for sealants by third parties, the public's knowledge about sealants, and patient education about sealants. Participants also were supplied with:

-reprints of scientific articles,

- the consensus development conference statement on dental sealants from the National Institutes of Health (17),

-a list of pit and fissure sealants deemed acceptable by the American Dental Association (ADA),

-a source list of patient education materials (18),

- the current regulations on use of dental auxiliaries in Michigan,

-samples of pamphlets and patient education materials, and

- two plaster tooth models for sealant demonstration.

Practitioners and their auxiliaries applied sealants to extracted teeth during a laboratory session.

Dentists who elected to acquire materials by mail could receive all the written materials distributed at the continuing education course, a videotape about sealants, and the tooth models. The videotape contained an abridged version of information presented in the continuing education programs. All dentists who attended courses or received materials also were sent six newsletters and a variety of other materials: reprints of scientific articles, a statement on sealants from the Surgeon General, additional patient education materials, and sources of education materials. Newsletter topics included technical considerations relating to sealant application, auxiliary utilization, sealing caries, and sealant longevity. To augment the service component of the program, dentists in the No-Education Group were offered the sealant videotape after the followup survey.

\section{Results}

Only results for general dentists are presented, as the number of pediatric dentists completing both surveys was small ( $n=23$ ). Table 1 displays response rates for the baseline and followup surveys: 62 percent and 76 percent, respectively. The population used for analysis totaled 1,014 subjects: 1,037 dentists who returned two surveys minus pediatric dentists. Analysis of nonrespondents to the two surveys indicated declining participation over time by older dentists $\left(\chi^{2}=165.00 ; \mathrm{df}=8\right.$; $P<.001)$. Dentists aged 55-64 years comprised about 21 percent of nonrespondents to the baseline and followup surveys, while accounting for 15 percent of the dentists who completed both surveys. As might be expected, participation by dentists aged 65 years or older declined markedly during the project. Dentists from the largest urban area of the state (southeast Michigan) were also less likely to complete both surveys $\left(\chi^{2}=23.1 ; \mathrm{df}=6\right.$; $P<.001)$. These dentists comprised 49 percent of nonrespondents to the baseline survey, 44 percent of nonrespondents to the followup survey, and 39 percent of respondents to both surveys. The numbers of subjects displayed in subsequent tables vary because some respondents did not complete all questions.

The total attendance for the eight continuing education courses was 139 dentists (Table 2). Written materials and videotapes were requested by 27 percent of the dentists, while about 12 percent of the Education Group requested

TABLE 1

Response Rates to Baseline and Followup Surveys

\begin{tabular}{|c|c|c|c|}
\hline Survey & Initial $N$ & $\begin{array}{l}\text { Surveys } \\
\text { Returned }\end{array}$ & $\begin{array}{c}\% \\
\text { Response }\end{array}$ \\
\hline Baseline & 2,203 & 1,361 & 61.8 \\
\hline Followup & 1,361 & 1,037 & 76.2 \\
\hline
\end{tabular}


TABLE 2

Distribution of General Practitioners by Participation Status and by Completion of Project Surveys

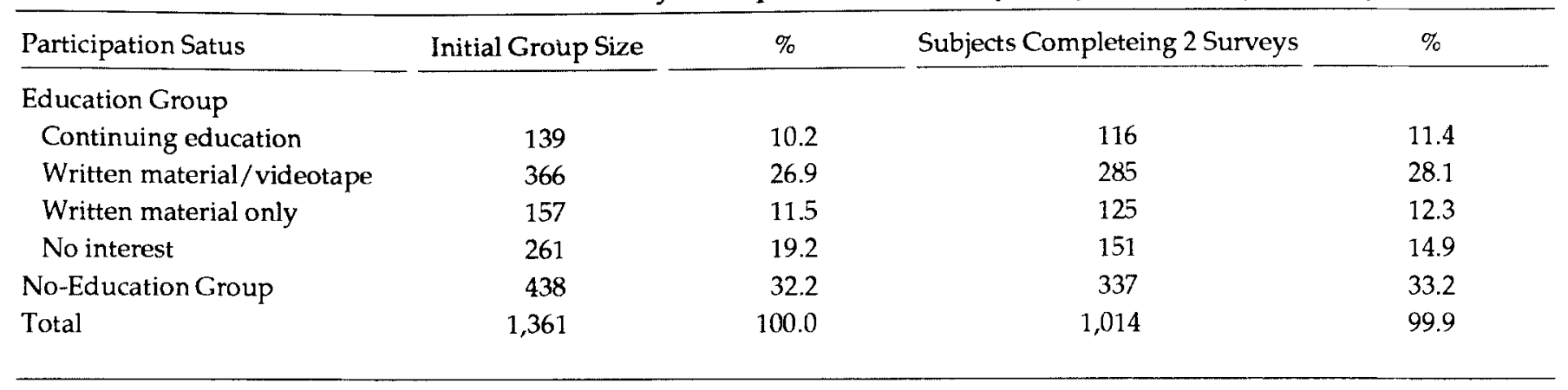

TABLE 3

Knowledge and Attitudes Scores, and Percent Sealant Use at Baseline and Followup Surveys

\begin{tabular}{|c|c|c|c|c|c|}
\hline & & \multicolumn{3}{|c|}{ Education } & \multirow[b]{2}{*}{ No Education } \\
\hline & & Continuing Educ. & Written/Video & Written & \\
\hline (range 0-12) & Followup & $9.2(2.1)^{*}$ & $9.2(2.0)$ & $9.1(2.2$ & $8.4(2.2)$ \\
\hline$n$ & & 116 & 285 & 125 & 337 \\
\hline Attitude scale & Baseline & $21.9(3.5)^{*}$ & $22.5(3.3)$ & $22.7(3.2)$ & $22.4(3.2)$ \\
\hline$n$ & & 113 & 272 & 121 & 325 \\
\hline Percent sealant & Baseline & $5.0+$ & 10.0 & 5.0 & 5.0 \\
\hline use & Followup & $10.0 \dagger$ & 10.0 & 10.0 & 10.0 \\
\hline$n$ & & 91 & 247 & 107 & 288 \\
\hline
\end{tabular}

*Mean (standard deviation).

tMedian.

only written materials. About 19 percent of those invited to participate declined or did not return a request for materials (No interest). At the followup survey, videotapes were requested by 315 respondents in the No-Education Group. Overall, courses or materials were provided to 977 ( 72 percent) of the 1,361 dentists who responded to the baseline survey.

Table 2 also shows the distribution of general practitioners who responded to both surveys, by their participation status. Dentists grouped as No Interest were not considered in subsequent analyses. One-third of respondents were in the No-Education Group ( $n=337)$. The mean age of respondents was 42.6 years and the average number of years since graduation was 16 years. The profile of auxiliary use was similar for Education and No-Education Groups. The proportions of respondents employing various auxiliaries were: dental hygienists, 90 percent; registered dental assistants, 57 percent; and dental assistants, 96 percent.

The baseline and followup values for knowledge scores, the attitude scale, and median percent sealant use are shown in Table 3 . All groups correctly answered about eight of the 12 knowledge questions (ANOVA,
$F$-statistic $=1.75 ; P=.16)$. The continuing education group exhibited the lowest baseline knowledge score (7.6). All baseline attitude values were positive and approximately midway between neutral (value $=18$ ) and the maximum positive value of 30 (ANOVA, $F$-statistic $=1.40 ; P=.24$ ). The proportions of patients aged 18 years or younger who were receiving sealants were identical for two education groups (continuing education, written material only) and the No-Education Group (median $=5.0 \%$ ). Dentists in the written material/videotape group reported placing more sealants (median $=10.0 \%$ ), but sealant placement values were not significantly different (median test statistic $=1.58 ; P=.66$ ). At baseline, about 11 percent of all groups were not using any sealants.

At the followup survey, all education groups had significantly higher knowledge scores than the No-Education Group (ANOVA, $F$-statistic $=7.63 ; P<.001$ ). Attitude values of all groups had increased slightly, but the only significant value was between the written material/videotape group and the No-Education Group (ANOVA, $F$-statistic $=3.11 ; P=.03)$. Sealant use by all groups was identical (median $=10 \%$ ). The numbers of respondents not using sealants declined slightly between surveys in 
TABLE 4

Percent of Subjects Responding Affirmatively to Questions about Practice Changes during the Program Year

\begin{tabular}{|c|c|c|c|c|c|}
\hline & \multicolumn{3}{|c|}{ Education } & \multirow[b]{2}{*}{ No Education } & \multirow[b]{2}{*}{$P\left(\chi^{2}\right.$ Test $)$} \\
\hline & Cont. Educ. & Written/Video & Written & & \\
\hline Better informed about sealants. & 86.8 & 79.4 & 73.3 & 38.8 & $<.001$ \\
\hline$n$ & 114 & 277 & 120 & 325 & \\
\hline Patient aceptance of sealants increased. & 64.0 & 57.5 & 53.3 & 53.8 & .56 \\
\hline$n$ & 114 & 275 & 120 & 333 & \\
\hline Use of sealants increased. & 64.0 & 66.8 & 61.2 & 58.4 & .28 \\
\hline$n$ & 114 & 277 & 121 & 332 & \\
\hline Tried but failed to increase sealant use. & 6.4 & 11.8 & 9.6 & 10.0 & .73 \\
\hline$n$ & 109 & 272 & 115 & 321 & \\
\hline
\end{tabular}

the three educations groups while rising slightly in the No-Education Group. Differences in the numbers of nonusers between all groups were minor $\left(\chi^{2}=10.87 ; \mathrm{df}=9\right.$; $P=.29$ ).

Table 4 presents the distribution of responses to four questions about practice changes during the year of the program. At least 70 percent of all participants agreed that they had become better informed about sealants during the program year, compared to only about 40 percent of respondents from the No-Education Group. The distribution of affirmative responses for this question was statistically significant. The distributions of responses to questions regarding increases in patient acceptance, increases in sealant use, and failure to increase sealant use were not found to be statistically significant.

\section{Discussion}

Generalizations from the findings are limited by certain attributes of the project. Voluntary participation, modest response rates to the surveys, and declining participation by older and urban dentists reduce the representativeness of the study population. Subjects were not randomly assigned to a particular educational component, a feature that created the potential for self-selection bias. Many variables of interest were acquired by self-report and thus should be interpreted with caution. Despite these limitations, the findings help in understanding the effectiveness of continuing education for dentists.

Aspects of innovation or technology diffusion theory are relevant to this discussion, although at least one distinction should be noted. Diffusion theory focuses primarily upon the process of technology adoption, rather than on increasing use of technology following its adoption. A primary objective of the project was to increase use, as most participants were already applying sealants, albeit infrequently.

The innovation-decision process consists of five stages: knowledge, persuasion (attitude formation), decision, implementation, and confirmation (19). Knowledge about an innovation can be divided into awareness, "how-to" knowledge, and principles knowledge. The program focused predominantly upon the second and third categories of knowledge, as findings from the baseline survey indicated that awareness of sealants was already widespread among respondents. Baseline knowledge scores suggested that functional understanding of sealant technology was also moderately high. All education groups had small improvements in their knowledge scores. Results mildly endorse the effectiveness of continuing education programs for inducing knowledge acquisition, and establish that knowledge may be increased by means other than direct contact with individuals. It must be observed, however, that followup knowledge scores of the three education groups were nearly identical. Thus, the knowledgegain demonstrated by each group may be related more to baseline knowledge deficits than to the mode of education that was selected. When improvements in knowledge scores and perceived information gain of the three education groups were compared to similar values of the No-Education Group, we concluded that knowledge acquisition was a program achievement.

\section{"The reluctance of third party insurers to reimburse for sealants has likely impeded utilization...."}

With the exception of one group (written material/video), participants' attitudes toward sealants varied little during the program year. There were no differences in perceptions of patient acceptance of sealants among the several groups. The absence of affective changes may be due to several factors. All groups had relatively positive attitudes toward sealants at baseline, so capacity for improvement was limited. Furthermore, affective changes are more difficult to accomplish than cognitive changes, and the time span of the program may not have permitted observation of such changes. 
Sealant use was not increased by participation in the program. Respondents' responses to questions about increased use or failure to increase use also confirmed the absence of differences between groups. In this instance, the knowledge-persuasion-practice continuum was not supported. Again, the time between surveys may have been insufficient to capture changes in behavior. Evaluation periods may need to be years in duration rather than months (20). There are other factors that may affect provider behavior. For example, the characteristics of an innovation may improve or impede the likelihood of diffusion (19). Is the innovation economically or socially beneficial to the user? Is the innovation compatible with existing professional values and norms, and will adoption of the innovation be observable by others? If sealant use is compared to rubber glove use for infection control, one might speculate that the latter innovation would be adopted more rapidly because of its social benefits, professional compatibility, and observability. Conversely, sealants may be compatible with professional values, but not be viewed as economically beneficial or observable by others. Additionally, forces outside the practice environment can act as catalysts for adoption or affect the rate of technology use. Authority decisions by external agencies are such forces. The reluctance of third party insurers to reimburse for sealants has likely impeded utilization, while promulgation of government regulations on infection control procedures has probably encouraged the use of rubber gloves.

Findings from the current investigation corroborate results of the North Carolina sealant initiative (15). In that program, knowledge scores of dentists who attended continuing education programs were significantly higher than the scores of nonparticipants, while attitude values of the two groups were similar. Increased sealant use was found to be no different between participants and nonparticipants. Because of the similarity of program outcomes, it can be concluded that for sealants, continuing education is likely to increase dentists' knowledge, but have little effect upon their attitudes or sealant use. Given the success of other educational interventions (20-22), the outcomes of our program may be a consequence of the singular nature of the innovation or the methods of promotion. Further research into the effectiveness of continuing dental education (CDE) is merited. Assessment of future endeavors must be rigorous, as CDE, in general, has suffered from infrequent and inadequate evaluation (23). Practitioners should be queried about desirable approaches to continuing education. These perceptions and baseline assessment surveys will permit change agencies to construct more effective, focused education programs. Further, lifelong learning should be a conceptual thread woven into the design of continuing education. Dentists who participate must be recognized for their self-direction, discipline, and intellectual curiosity (24). Given the minimal effects achieved by many education programs, nurturing the concept that health professionals should be continual learners may well be the most important achievement of these endeavors.

\section{Acknowledgments}

The authors acknowledge the valuable contributions made to the project by Jeffery Kopmanis and April Pixley. Also, the authors thank the anonymous referees for contributing to the improvement of this manuscript.

\section{References}

1. Gift HC, Frew R, Hefferren JJ. Attitudes toward and use of pit and fissure sealants. J Dent Child 1975;42:460-6.

2. Simonsen RJ. Pit and fissure sealants: attitudes toward and use by dentists in Minnesota. Quintessence Int 1983;4:473-9.

3. Gift HC, Frew, RA. Sealants: changing patterns. J Am Dent Assoc 1986;112:391-2.

4. Hunt RJ, Kohout FJ, Beck JD. The use of pit and fissure sealants in private dental practices. J Dent Child 1984;51:29-33.

5. Rubenstein LK, Dinius A. Dental sealant usage in Virginia. J Public Health Dent 1986;49(1):147-51

6. Cohen L, Labelle A, Romberg E. The use of pit and fissure sealants in private practice: a national survey. J Public Health Dent 1988;48(1):26-35.

7. Lang WP, Farghaly MM, Ziemiecki TL, Dennison JD. Prevalence of fissure sealant use among Michigan dentists [Abstract]. J Dent Res 1988;67(Spec Iss): 192.

8. Badner VM, Rosenberg D. Dentist use patterns for pit and fissure sealants and topical fluorides. J Dent Educ 1986;50:656-60.

9. Selwitz RH, Colley-Niemeyer BJ, Rozier RG. Prevalence of and need for dental sealants in schoolchildren [Abstract]. J Dent Educ 1988;67(Spec Iss): 192

10. Weintraub JA, Burt BA. Prevention of dental caries by the use of pit-and-fissure sealants. J Public Health Policy 1987;8:542-60.

11. Horowitz AM, Frazier PJ. Issues in the widespread adoption of pit and fissure sealants. J Public Health Dent 1982;42:312-23.

12. Frazier PJ. Use of sealants: societal and professional factors. J Dent Educ 1984;48(Suppl):80-95.

13. Scheirton L. Training and educational needs in pit and fissure sealant application for graduate dental personnel: continuing education and certification courses. J Dent Educ 1984;48(Suppl):66-74.

14. Callanen VA, Weintraub JA, French DP, Connolly GN. Developing a sealant program: the Massachusetts approach. J Public Health Dent 1986;46(3):141-6.

15. Bader JD, Sams DH, O'Neil EH. Estimates of the effects of a statewide sealant initiative on dentists' knowledge and attitudes. J Public Health Dent 1987;47:186-92.

16. Michigan Department of Licensing and Regulation. County statistics for dentists, dental specialties, and dental hygienists. Lansing: State of Michigan, 1985.

17. National Institutes of Health. Consensus development conference statement on dental sealants in the prevention of tooth decay. J Am Dent Assoc 1984;108:233-6.

18. Massachusetts Department of Public Health. Preventing pit and fissure caries: a guide to sealant use. Boston: Massachusetts Department of Public Health, 1986.

19. Rogers EM. Diffusion of innovations. New York: The Free Press, 1983:163-209.

20. Chapko MK, Milgrom P, Bergner M, Conrad D, Skalabrin N. The effects of continuing education in dental practice management. J Dent Educ 1984;48:659-64.

21. Gerbert B, Maguire B, Badner V, et al. Changing dentists' knowledge, attitudes, and behaviors relating to AIDS: a controlled educational intervention. J Am Dent Assoc 1988;116:851-4.

22. Milgrom $P$, Weinstein $P$, Ratener $P$. Quality assessment as a form of continuing dental education: changing dentist clinical performance. J Am Dent Assoc 1980;101:258-64.

23. Bader JD. A review of evaluations of effectiveness in continuing dental education. Möbius 1987;7:39-48.

24. Abbey LM. Informatics in dental education: a horizon of opportunity. In: Salamon R, Protti D, Moehr J, eds. Proceedings. Medical informatics and education. International symposium. Victoria: University of Victoria, 1989 